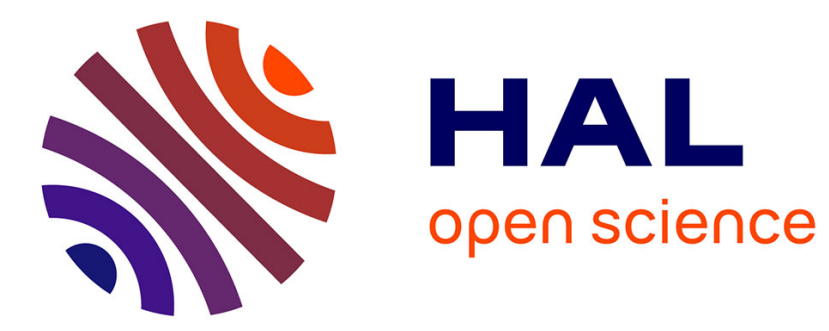

\title{
Performances of a Hybrid Excited Flux-Switching DC-Alternator: Analysis and Experiments
}

\author{
Agathe Dupas, Emmanuel Hoang, Sami Hlioui, Benjamin Gaussens, Michel \\ Lécrivain, Mohamed Gabsi
}

\section{- To cite this version:}

Agathe Dupas, Emmanuel Hoang, Sami Hlioui, Benjamin Gaussens, Michel Lécrivain, et al.. Performances of a Hybrid Excited Flux-Switching DC-Alternator: Analysis and Experiments. ICEM, Sep 2014, Berlin, Germany. hal-01062209

\section{HAL Id: hal-01062209 \\ https://hal.science/hal-01062209}

Submitted on 9 Sep 2014

HAL is a multi-disciplinary open access archive for the deposit and dissemination of scientific research documents, whether they are published or not. The documents may come from teaching and research institutions in France or abroad, or from public or private research centers.
L'archive ouverte pluridisciplinaire HAL, est destinée au dépôt et à la diffusion de documents scientifiques de niveau recherche, publiés ou non, émanant des établissements d'enseignement et de recherche français ou étrangers, des laboratoires publics ou privés. 


\title{
Performances of a Hybrid Excited Flux-Switching DC-Alternator: Analysis and Experiments
}

\author{
A. Dupas, E. Hoang, S. Hlioui, B. Gaussens, M. Lécrivain, M. Gabsi
}

\begin{abstract}
In this paper, a finite elements analysis and experimental results of a hybrid excited flux switching $3 \mathrm{~kW}$ DCalternator are presented. The studied machine is presented and its flux control capability is calculated. The short-circuit current is explored by mean of two different methods. One of them cancels all harmonic components of the flux. The second part presents the alternator connected to a diode bridge rectifier with a DC controlled bus. The performances of the studied machine are evaluated by the model and compared to experimental results. Finally, we compared the experimental performance of the studied machine with $\mathrm{NdFeB}$ magnets, ferrite magnets and without magnet.
\end{abstract}

Index Terms-Hybrid excitation machine, synchronous alternator, 2D-FEA, Rectifiers

\section{INTRODUCTION}

TABLE I

NOMENCLATURE

$\begin{array}{ll}\text { 2-D FEA } & \text { Two-dimensional finite-element analysis. } \\ \text { PM } & \text { Permanent magnet. } \\ \text { HEM } & \text { Hybrid excitation machines } \\ \text { HEFSPM } & \text { Hybrid excited flux-switching permanent magnet. } \\ \text { DBR } & \text { Diode bridge rectifier. } \\ \text { Jexc } & \text { Excitation current density. } \\ \text { Jcc } & \text { Short-circuit current density. } \\ \text { Icc } & \text { Short-circuit current. }\end{array}$

D EVELOPMENT of the embedded systems and the increase of the power production from the wind energy (for example, http://www.venpower.com/ or [1]) make essential research about compact, reliable and powerful alternator. In the quoted examples, it is necessary to work in variable speed and thus to be able to regulate the output voltage of the alternator by means of the flux modulation. In this paper, a hybrid system solution is investigated.

Hybrid excitation machines (HEM) combines advantages of wound excitation machines and permanent-magnet excited machines. Electric excitation offers a better control of the magnetic field by controlling the excitation current while permanent magnet has a high-energy density. Many hybrid excited topologies were proposed in the literature and compared with PM machines [2]-[6]. The idea is to combine the two excitation flux in order to have a high density synchronous machines with good flux control. Researchers have investigated HEM connected to a diode rectifier [17] [18]. One of these topologies is flux-switching machine [7]-[14]. Due to a salient passive rotor, hybrid excited flux-switching permanent magnet machines have high robustness and thanks to permanent magnets localised on the stator the HEFSPM have high torque density. Thanks to these advantages, this machine is a good candidate for a DC-alternator application capability.

Two intrinsic major characteristics are important during an alternator exploration, the no-load flux and short-circuit current. The aim of this article is to examine these two characteristics for a HEFSPM prototype with $\mathrm{NdFeB}$ permanent magnet. The output power of HEFSPM connected to a diode bridge rectifier is also explored. A comparison of the output power, no-load flux and short-circuit current calculated with FEA and obtained by measurement is exposed.

The second part of this paper consists to present differences between three permanent magnet configurations. A FEA and measurement comparison between rare-earth magnets and ferrite is proposed. In order to identify the benefits of the hybrid excitation experimental measurements and FEA were performed with and without permanent magnet.

\section{Structure of the Hybrid Excited FluX-SWITCHING PERMANENT MAGNET PROTOTYPE AND EXPERIMENTAL BENCH}

\section{A. Structure presentation}

The proposed HEFSPM has 24 stator slots and 20 rotor poles. Two magnetomotive sources are located on the stator, one is produced by permanent magnets and the other one by electrical excitation windings. The rotor is composed by 20 salient poles, and has neither windings nor permanent magnets. The structure investigated in this paper was already reported in [15][16]. The prototype and specifications are shown in Fig.1 and Tab.II.

TABLE II

PROTOTYPE MACHINE SPECIFICATIONS

\begin{tabular}{ll}
\hline \hline Number of phases & 3 \\
Number of stator slot & 24 \\
Number of rotor teeth & 20 \\
External stator radius & $180 \mathrm{~mm}$ \\
External rotor radius & $115 \mathrm{~mm}$ \\
Air gap & $0.5 \mathrm{~mm}$ \\
Active axial length & $15 \mathrm{~mm}$ \\
\hline \hline
\end{tabular}

\section{B. Presentation of the experimental benchmark}

This paper will focus on generator mode. For experiment, the HEFSPM is associated with a diode-bridge rectifier.[16][18] The scheme of the experimental bench is given in Fig.2 As prime mover of HEFSPM generator, an induction motor of $5.5 \mathrm{~kW}$ is employed. The DBR is connected on the same DC-bus voltage feeding the 3-phase inverter controlling the induction motor. 


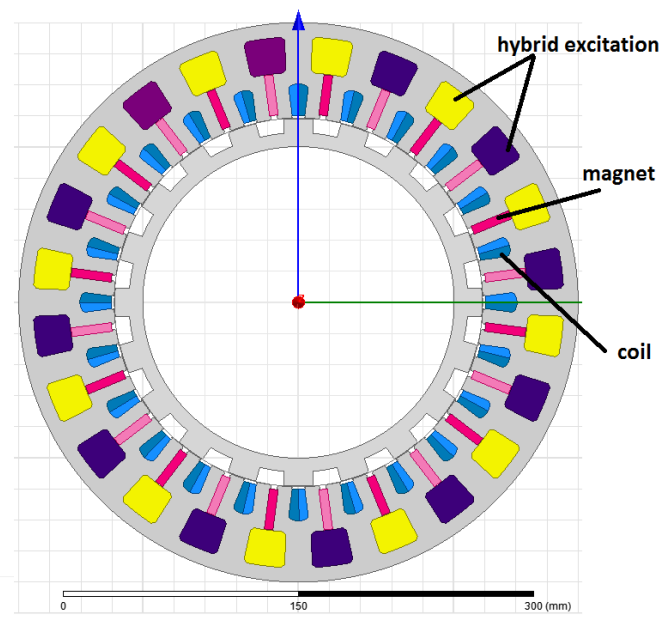

Fig. 1. 2D view of the Hybrid Excited Flux-Switching Permanent Magnet Generator prototype 24-20

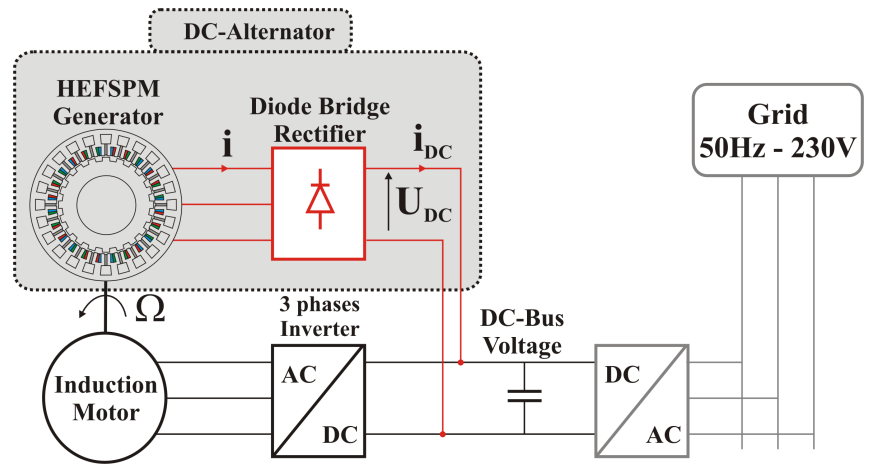

Fig. 2. Schematic diagram of the power generation system

\section{III. “The NDFEB-HEFSPM PROTOTYPE"}

\section{A. No-load flux}

The main advantage of the hybrid excitation is, as wounded excitation for synchronous machine, the flux regulation capability. The flux distribution of the prototype machine at different excitation currents are shown in Fig.3 and Fig.4.

We can notice that without excitation current, the main permanent magnet flux is short-circuited in the external stator yoke. Thanks to excitation current, air-gap magnetic field is adjustable.

All measured and calculated maximum flux correspond to the rotor's position given in Fig.3, a stator slot and a rotor teeth are aligned. The no-load flux value is calculated for one conductor in one slot.

Figure 5 shows the no-load flux for different excitation current density values (0 to $\left.6 \mathrm{~A} / \mathrm{mm}^{2}\right)$. When the excitation currents equal to $0 \mathrm{~A} / \mathrm{mm}^{2}$, the no-load flux is due to the permanent magnet. When we supply the exciting windings, the no-load flux increases.

Figure 6 presents differences between FEA model and experimental results. Differences between curves can be explained by the lack of precision on $\mathrm{B}(\mathrm{H})$ characteristic and the $3 \mathrm{D}$ effect. Actually, the studied structure has $15 \mathrm{~mm}$ axial length and $180 \mathrm{~mm}$ external radius, thus the 3D effects are important. Further investigations are needed to estimate the impact of the $\mathrm{B}(\mathrm{H})$ characteristic and 3D effects on FEA results. However, the difference is less than $5 \%$ and it is considered as acceptable in this study.

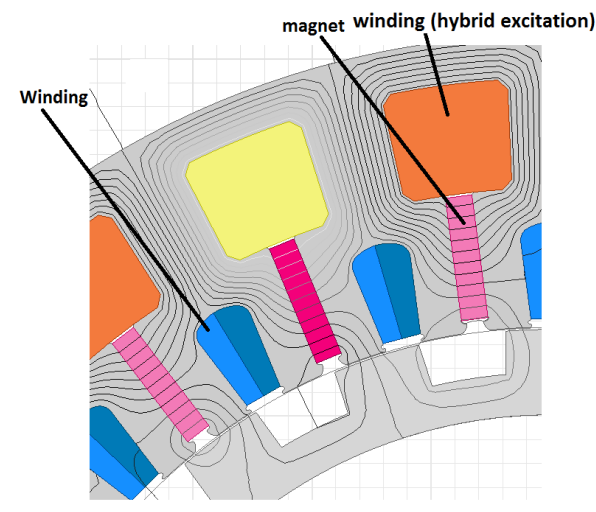

Fig. 3. FEA: Flux distributions for $J_{\text {exc }}=0 \mathrm{~A} / \mathrm{mm}^{2}$

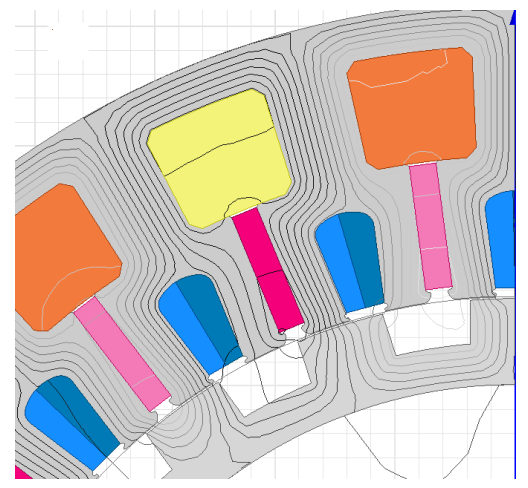

Fig. 4. FEA: Flux distributions for $J_{e x c}=10 \mathrm{~A} / \mathrm{mm}^{2}$

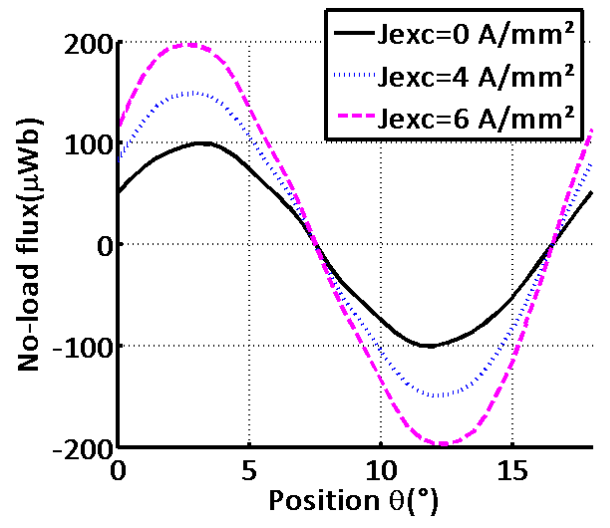

Fig. 5. FEA: Evolution of no-load flux (per turn) as function of mechanical position $\theta$ under different exciation current density 


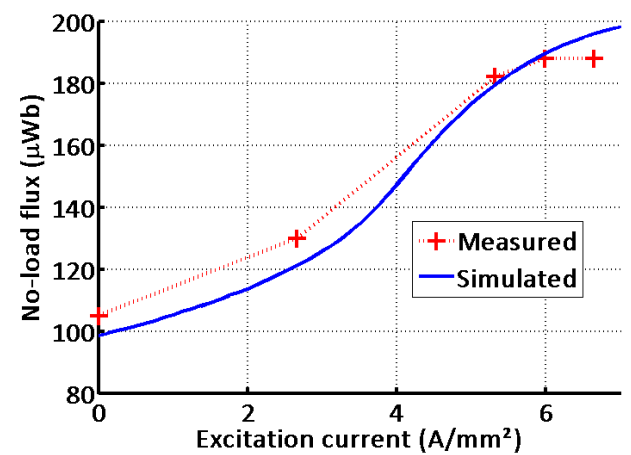

Fig. 6. Maximum no-load flux versus excitation current density, comparison between model and experimental results

\section{B. Short-Circuit Current}

The experimental bench scheme is given Fig.2. In order to explore the output power, the DC-bus is replaced by a shortcircuit in experimental bench. Relations between output power and short-circuit current are explored in [16].

Two methods are used to calculate the short-circuit current density. The short-circuit current corresponds to the current that cancels total excitation flux in the machine. The first method consists of firstly to determine the $d$-axis position. Secondly, three-phase currents, in phase opposition with the no-load flux, are injected. Thirdly the total excitation flux in the machine is computed and compared to zero (in this case only the fundamental part of the flux is considered). If the flux is nul, the short-circuit current is obtained, otherwise the amplitude of the current increased until the fundamental component of the flux is cancelled. Indeed the harmonics are almost no impacted.

Figure 7 presents results obtained by the first method, the calculated short-circuit current density is compared to the measured. An important difference can be noticed between simulation and experimental results. This difference may be explained by the harmonics.

The second method is similar to the experimental method. The output of the armature windings are in short-circuit and the current is computed by the circuit model. The FEA are coupled to a circuit model, the simulations are performed in transient. This method allows to obtain the current that cancels all harmonics of the flux. Figure 8 shows one short-circuit current for Jexc $=0 \mathrm{~A} / \mathrm{mm}^{2}$. The result obtained from the FEA shows that the short-circuit current is not sinusoidal. As we can see on Fig.9, short-circuit current waveform is distorted and the spectra of $I_{c c}$ contains harmonic contents. . The results of the two methods are compared with experimental results in Fig10. The second method overestimate $I_{c c}$, as the first method, but the difference is more acceptable. This difference can be explained by the end winding inductances that is neglected in the 2D model. The end windings measure approximatively $20 \mathrm{~mm}$ when the active length is $15 \mathrm{~mm}$.

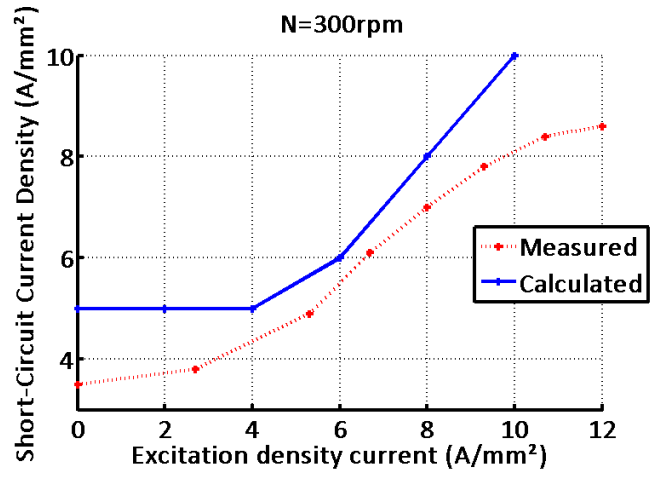

Fig. 7. Evolution of short-circuit current density as function of excitation current, comparison between models and experimental results

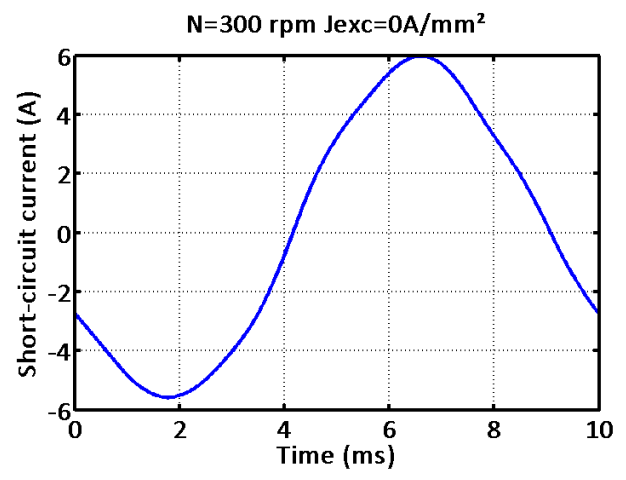

Fig. 8. FEA: Evolution of short-circuit current as function of time

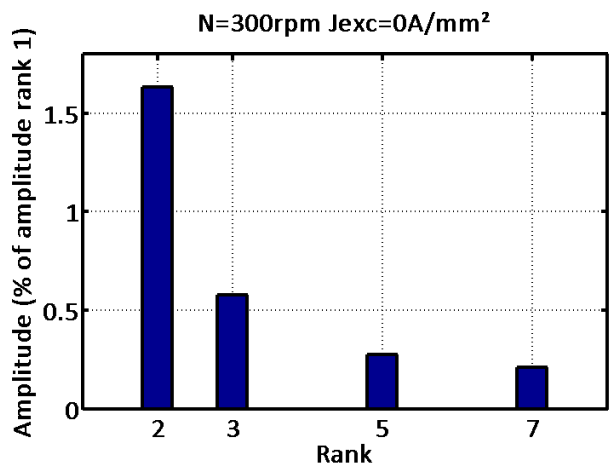

Fig. 9. FEA: Spectra of short-circuit current

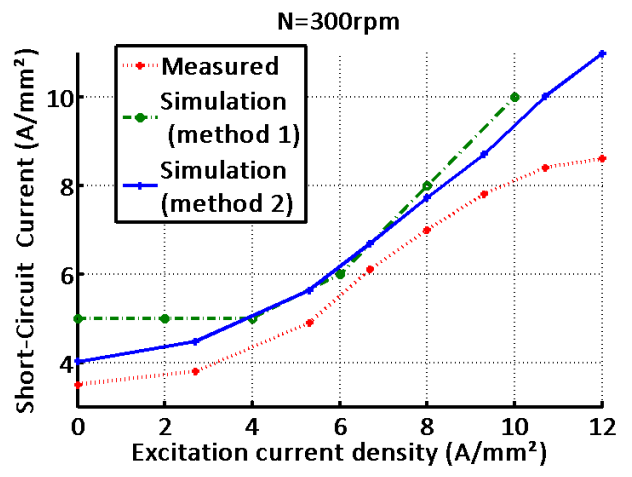

Fig. 10. Short-circuit current density as function of excitation current density, comparison between measurements and simulations 


\section{Machine connected to a Diode Rectifier}

In this section the HEFSPM Generator is used with the DBR as presented in Fig.2. The DC-bus voltage equals 300V. A DC excitation current is applied to wounded excitation and output power is calculated with FEA model for a speed: $\mathrm{N}=2000 \mathrm{rpm}$. Figure 11 presents output power waveforms for different $J_{\text {exc }}$. We can notice that if the excitation current are greater than $12 \mathrm{~A} / \mathrm{mm}^{2}$, the output power decreases. This is due to magnetic saturation phenomena in the stator of the HEFSPM, the saturation is located in the upper stator yoke. Moreover, the relation between electric period oscillation and the mechanics period is verified, $T_{e}=\frac{T_{m}}{6 N_{R}}$. For example, at $\mathrm{N}=2000 \mathrm{rpm}$, $T_{e}=0.25 \mathrm{~ms}$, as shown in Fig. 11 .

From FEA, the output power as function of the speed $\mathrm{N}$ can be obtained. Its evolution is presented in Fig12. The values obtained from the FEA are higher than experimental results, this difference is due to all neglected losses, that are not take into account in our model. Moreover differences between experimental and simulated values of no-load flux and shortcircuit current are cumulative. So this significant difference can be explain.

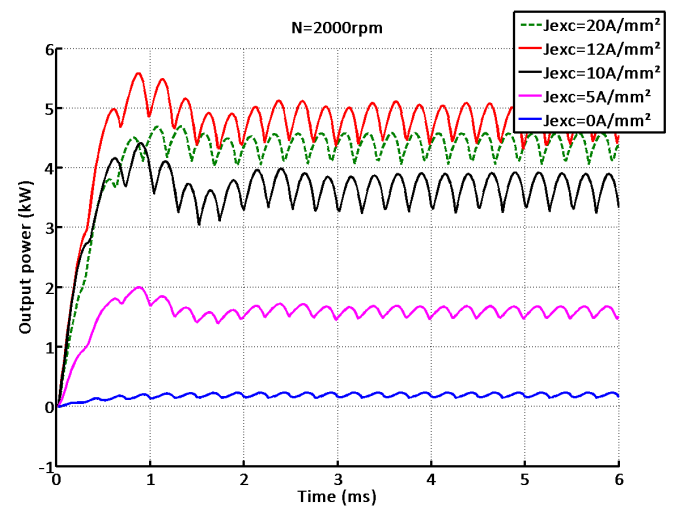

Fig. 11. FEA: Output power evolution for $J_{e x c}$ different values (N=2000rpm)

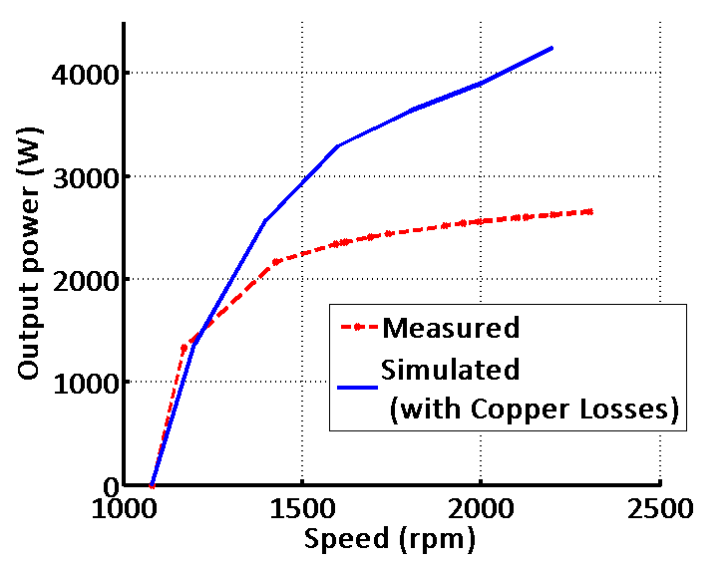

Fig. 12. Output power of the DC-Alternator as function of speed, comparison between FEA and measurement

\section{COMPARISON WITH “FERRITE" AND "NO PERMANENT MAGNET PROTOTYPES"}

The previous part has analysed the main intrinsic characteristics of a NdFeB-HEFSPM prototype. In this part a comparison between three prototypes are presented in order to show the impact of the permanent magnet type on the power generation capability of this machine. The difference between these prototypes is the permanent magnet type: $\mathrm{NdFeB}$, Ferrite and the last one have not permanent magnets.

Please notice that the machine was optimised for a hybrid excitation use. Thus, this comparison between the three configurations could be improved by the optimization of each machine according to its permanent magnet configuration.

\section{A. No-load flux}

The figure 13 and 14 provide no-load flux comparison between the three permanent magnet configurations. Before $4 \mathrm{~A} / \mathrm{mm}^{2}$, the difference between ferrite and no-magnet is not significant but, for higher current density the hybrid excitation contribution is important. With $\mathrm{NdFeB}$ permanent magnet, the main advantage is the no load flux is higher even if $J e x c=0 A / \mathrm{mm}^{2}$. The no-load flux with ferrite isn't equal to zero at $J e x c=0 A / \mathrm{mm}^{2}$ but only $10 \mu \mathrm{Wb}$.

Another important finding was that the permanent magnet type affect the control capability flux. Although rare-earth magnets provide a more important flux at $0 \mathrm{~A} / \mathrm{mm}^{2}$, the flux variation range is only $100 \mu \mathrm{Wb}$ while with ferrite it is $180 \mu \mathrm{Wb}$.

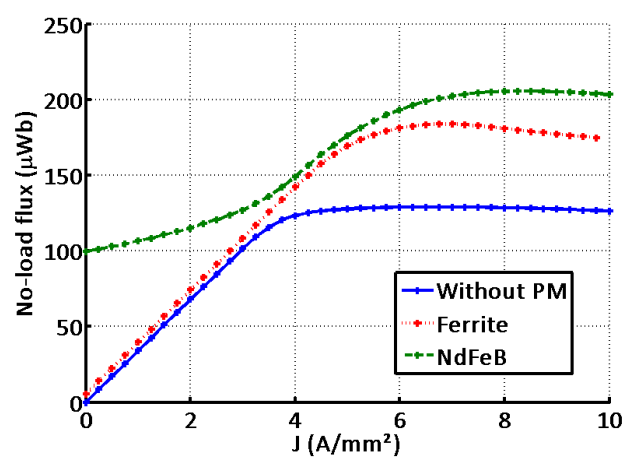

Fig. 13. FEA: Maximum no load flux versus excitation current density

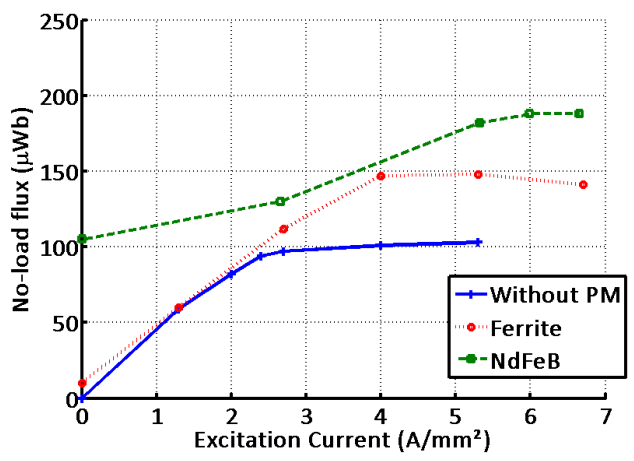

Fig. 14. Experimental results: Maximum no load flux versus excitation current density 


\section{B. Short-circuit current}

As described on the previous part, the short-circuit current is measured for the three configurations. The mean value of $J_{c c}$ is measured as function of excitation current and its evolution is given Fig. 15.

As remind on the previous section, the short-circuit can be linked with output power. So, as predicted, the main advantage of hybrid excitation is the output power control capability, the output power increase with excitation current. The range with $\mathrm{NdFeB}$ is almost $5 \mathrm{~A}$ whereas without magnet the range is $3 \mathrm{~A}$ so the range of power control is larger with hybrid excitation.

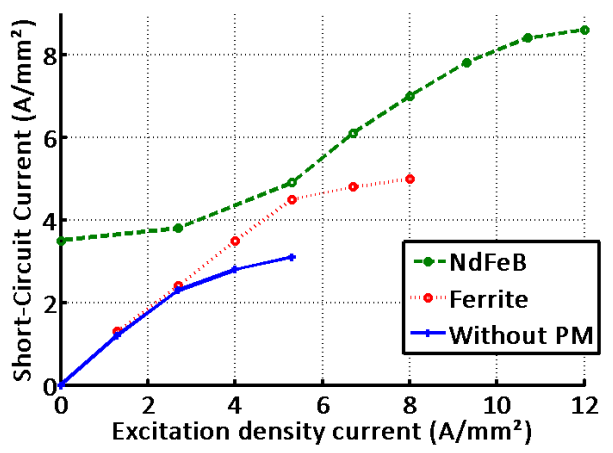

Fig. 15. Experimental results: Short-circuit Current versus excitation current density

\section{Output power}

The same experimental bench as Fig.2 is used in this section. The output power is compared for two permanent magnet configurations. The advantage of rare-earth magnet is highlighted on Fig16. This figure confirms that, depending on the desired output the type of magnet will be different and thereby the cost.

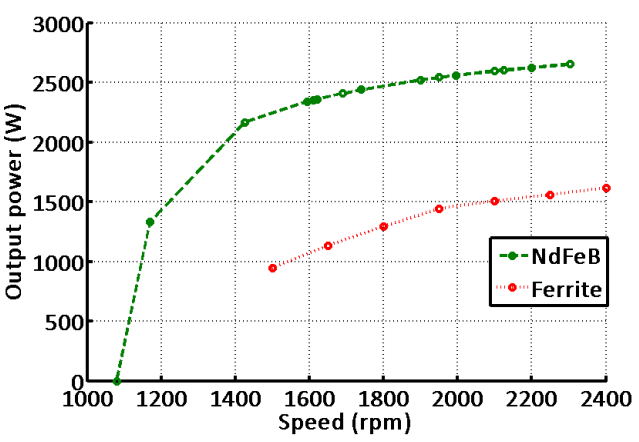

Fig. 16. Experimental results: Output power versus speed

\section{CONCLUSION}

In this paper, a 24 stator slots and 20 rotor poles hybrid excited flux-switching permanent magnet (HEFSPM) was presented. This study set out to determine performances of this prototype. FEA models are determined in order to assess noload flux and short-circuit current. In generator mode, the
HEFSPM is connected to a diode bridge rectifier with constant DC-voltage and output power is examined. The comparison of the predicted no-load flux values with experimental results gave us a good agreement. A further study could assess 3D effect in order to improve short-circuit current and output power calculations.

In the second part of this paper, three permanent magnet configurations were presented. The no-load flux, short-circuit current and output power were compared. Thanks to this comparison the influence of hybrid excitation machine is examined.

\section{ACKNOWLEDGMENT}

This machine was built in partnership with Leroy-SomerEmerson (Angouleme-France).

\section{REFERENCES}

[1] Ditmanson, C. Hein, P. Kolb, S. Molck, J. and Bernet, S.,"A new modular flux-switching permanent magnet drive for large wind turbines", Energy Conversion Congress and Exposition, pp. 896-903, 2013

[2] Amara, Y. Vido, L. Gabsi, M. Hoang, E. and Ben Ahmed, A. and Lécrivain, Michel, "Hybrid Excitation Synchronous Machines : EnergyEfficient Solution for Vehicles Propulsion", IEEE Transactions on vehicular technology, pp. 2137-2149, 2009

[3] Hlioui, S. Amara, Y. Hoang, E. Gabsi, M., "Overview of hybrid excitation synchronous machines technology", International Conference on Electrical Engineering and Software Applications, pp. 1-10,2013

[4] Hlioui, S. Vido, L. Amara, Y. Gabsi, M. Lécrivain, M. and Miraoui, A., "PM and hybrid excitation synchronous machines: Performances comparison", 18th International Conference on Electrical Machines, pp. 1-6, 2008

[5] Yang, T. Emilia, M. Johannes J.H. P. and Elena A. L., "Comparison of flux-switching machines and permanent magnet synchronous machines in an in-wheel traction application", The International Journal for Computation and Mathematics in Electrical and Electronic Engineering, pp.153165,2013

[6] Zhao, C. and Yan, Y., "A Review of Development of Hybrid Excitation Synchronous Machine", Proceedings of the IEEE International Symposium on Industrial Electronics, pp. 857-862, 2005

[7] Chen, J.T. Zhu, Z.Q., Howe, D. , "Stator and Rotor Pole Combinations for Multi-Tooth Flux-Switching Permanent-Magnet Brushless AC Machines", IEEE Transactions on Magnetics, pp. 4659-4667, 2008

[8] Gaussens, B. Hoang, E. Lécrivain, M. Manfe, P. and Gabsi, M., "A Hybrid-Excited Flux-Switching Machine for High Speed DC-Alternator Applications", IEEE Transactions on industrial electronics, 2014

[9] Geng, W. Zhuoran, Z. Yu, L., "A new parallel hybrid excitation brushless DC machine," Electrical Machines and Systems (ICEMS), pp.1-6, 2012

[10] Hua, W. Cheng, M. Zhu, Z.Q., "Analysis and Optimization of Back EMF Waveform of a Flux-Switching Permanent Magnet Motor", IEEE Transactions on Energy Conversion, pp. 727-733, 2008

[11] Hua, W. Cheng, M. Zhang, G., "A Novel Hybrid Excitation FluxSwitching Motor for Hybrid Vehicles", IEEE Transactions on Magnetics, pp. $4728-4731,2009$

[12] Owen, R. L. Zhu, Z. Q. and Jewell, G. W., "Hybrid-Excited FluxSwitching Permanent-Magnet Machines With Iron Flux Bridges", IEEE Transactions on Magnetics, pp. 1726-1729, 2010

[13] Finken, T. and Hameyer K., "Study of Hybrid Excited Synchronous Alternators for Automotive Applications Using Coupled FE and Circuit Simulation", IEEE Transactions on Magnetics, 2008 icem 2014

[14] Sulaiman, E. Kosaka, T. Matsui, N. and Ahmad, M. Z., "Design Improvement and Performance Analysis of 12 Slot -10 Pole Permanent Magnet Flux Switching Machine with Field Excitation Coils", The 5th International Power Engineering and Optimization Conference (PEOCO2011), 2011

[15] Hoang, E. Lécrivain, M.and Gabsi, M., "A new structure of a switching flux synchronous polyphased machine with hybrid excitation", EPE, pp. $1-8,2007$ 
[16] Gaussens, B. Hoang, E. Manfé, P. Lécrivain, M. and Gabsi, M., ’Improved Output Power Capability of Hybrid Excited Flux-Switching DCAlternators : Analysis and Experiments", Industrial Technology (ICIT), pp.960-965, 2012

[17] Gaussens, B. Hoang, E. Manfé, P. Lécrivain, M. and Gabsi, M., ”An Hybrid-Excited Flux-Switching Machine for High Speed DC-Alternator Applications", IEEE Transactions on Industrial Electronics, 2013

[18] Amara, Y. Ben Ahmed, A. H. Hoang, E. Vido, L. and Gabsi, M. and Lécrivain, M, "Hybrid Excitation Synchronous Alternator Debiting on a Diode Rectifier with a Resistive Load", EPE, 2003

[19] Pejovic, P. and Kolar, J.W., "Exact Analysis of Three-Phase Rectifiers With Constant Voltage Loads", IEEE Transactions on Circuits and Systems II: Express Briefs, pp. 743-747, 2008

\section{BIOGRAPHIES}

Agathe Dupas is currently working toward the $\mathrm{Ph} . \mathrm{D}$. degree in electrical engineering at SATIE laboratory, from the Ecole Normale Superieur of Cachan, France. She received a M.Sc. degree from the ENS in 2012. Her current research interests include modelling of innovative topology of machines with 2D and 3D FEA models.

Emmanuel Hoang was born in Antibes, France, in 1966. He received the agrgation and Ph.D. degree from the Ecole Normale Superieure de Cachan, Cachan, France, in 1990 and 1995, respectively, both in electrical engineering.Since 1990, he has worked with the electrical machine team in the SATIE Laboratory. His research interests include the modelling of the iron losses in switched reluctance machines (SRMs) and the design, modelling, optimization, and control of novel topologies of PM machines.
Sami Hlioui is lecturer in the CNAM, Paris and researcher in the SATIE laboratory of the ENS, Cachan, France. He obtained his electromechanical engineer diploma from the National School of Engineering of Sfax - Tunisia (ENIS) in 2004, his M.Sc. degree in electrical engineering from the ENS de Cachan - France and his Ph.D. degree in electrical power engineering from the University of Technology of Belfort-Montbeliard - France (UTBM) in 2008. His main research interest are the multidisciplinary modelling of electromagnetic actuators and the optimal design of these actuators for embedded applications.

Benjamin Gaussens was born in Toulouse, France, in 1987. He received the M.Sc. degree in electrical engineering from the Institut National Polytechnique (ENSEEIHT), Toulouse, France and the Ph.D. degree in electrical engineering from the Ecole Normale Superieure de Cachan, Cachan, France. His current research interests include design of innovative topology of electromagnetic actuators and their modeling.

Michel Lécrivain was born in Barneville, France. He received the degree in electrical engineering from the CNAM, Paris, France, in 1981. In 1997 he joined SATIE laboratory, ENS de Cachan, Cachan, France, as a research engineer. His research interests include the design and control of new hybrid machines and novel permanent magnet machines for automotive application

Mohamed Gabsi received the Ph.D. degree in electrical engineering from University of Paris-VI, Paris, France, in 1987, and the HDR from the University of Paris-XI, Orsay, France, in 1999. Since 1990, he has been working with the electrical machine team SETE of SATIE Laboratory, UniverSud, Cachan, France, where he is currently a Full Professor. His research interests include SRM, vibrations and acoustic noise, and PM machines 